\title{
LEYENDO A ALFONSO REYES: EL PASADO HECHO PRESENTE
}

Entre los maestros de nuestra literatura pocos han sufrido más la condenación paradójica de ser monumentos nacionales poco leídos que Alfonso Reyes. En parte se debe a las modas intelectuales que padecen todas las culturas de occidente, pero en parte también se debe a la insólita audacia de don Alfonso. Me propongo comentar aquí un ensayo suyo publicado en Sur, revista intelectual por excelencia, en diciembre de 1940 en Buenos Aires, con el título de "Sumario de la literatura". Posteriormente, con el título "Apolo o de la literatura", formó parte de La experiencia literaria, y ahora está incorporado al tomo 14 de las Obras completas de Alfonso Reyes.

Mi comentario será un estudio de dialéctica histórica en el que se toma en cuenta tanto la historicidad del texto como la historicidad del comentador. El ensayo alfonsino consiste en treinta y dos párrafos numerados, lo cual facilitará mi trabajo; sigo la enumeración de Reyes. No pretendo mejorar la prosa de don Alfonso haciendo una paráfrasis de sus observaciones, ni tampoco considero prudente añadir más ejemplos a los que él da. Mi papel será el de dialogar a través y por medio de la distancia temporal de cincuenta años que nos une.

1. Se distingue la literatura de las otras actividades del espíritu, nos dice Reyes, porque la literatura se ocupa de un suceder imaginario aunque integrado por los elementos de la realidad. Está bien, hasta aquí; la literatura se ocupa de la creación integrada por los elementos de la realidad. Pero en seguida, don Alfonso hace una aclaración clave: la literatura posee un valor de significado y un valor formal. Es decir, hay un medio significante de la construcción verbal y, a la vez, hay un significado de estos significantes. La siguiente línea se tiene que citar: "El común denominador de ambos valores está en la intención". Intención, pala- 
bra cargada de discusión filosófica y disputa teórica ${ }^{1}$, se usa de una manera inesperada. La intención, según los diccionarios, es la expresa determinación de hacer algo por alguien. Intención de quién, nos preguntamos, y cómo se perciben las intenciones cuando está ausente el ser que determina actuar. Alfonso Reyes aclara esto hasta cierto punto al decir que intención semántica se refiere al suceder ficticio y que la intención formal se refiere a la expresión estética. Al no postular como sede de la intención al autor, sino a la obra misma, nos recuerda que la obra artística, aun en ausencia de sus creadores, señala diseño, propósito, plan de acción, función comunal y mucho más. Claro está, esta observación no sorprende al arqueólogo que está acostumbrado a trabajar en la reconstrucción de obras y objetos de hechura humana cuyos autores han desaparecido, en muchos casos dejando como su única huella cultural esos fragmentos. Hay una diferencia fundamental entre fantasear sobre cómo fue el hombre o la mujer que hizo una pintura rupestre o aquel jarro de barro cocido, y el esfuerzo riguroso de descubrir el diseño, plan, propósito, etc., del objeto para que nos informe sobre la comunidad del artista. Por lo tanto, demos una respuesta a Reyes: hablemos de inten-

${ }^{1} \mathrm{El}$ concepto de intencionalidad ha sido uno de los fundamentos de la fenomenología de Husserl. Su discusión empezó con su comentario de La crítica de la razón pura de Emanuel Kant. Husserl desarrolla el concepto de intencionalidad como la designación de diseño o propósito de elaboración tal y como lo expresa la obra humana. Véase EDMUND HuSSERL, The phenomenology of internal time consciousness, ed. M. Heidegger, Indiana University Press, Bloomington, 1964 , pp. 52-54 y Cartesian meditations: an introduction to phenomenology, Martinus Nijhoff, the Hague, 1960, pp. 108-111. Especialmente pertinente a nuestra discusión es la elaboración que ha hecho Paul Ricoeur en Temps et récit, t. 3, Seuil, París, 1985; la tr. citada aquí proviene de Time and narrative, University of Chicago Press, Chicago, 1988, t. 3, pp. 101-102: “. . . historical intentionality only becomes effective by incorporating into its intended object the resources of fictionalization stemming from the narrative form of imagination, while the intentionality of fiction produces its effects of detecting and transforming acting and suffering only by symmetrically assuming the resources of historicization presented it by attempts to reconstruct the actual past". Véase también el uso del término por el comparatista norteamericano WALTER L. REED, $A n$ exemplary history of the novel, University of Chicago Press, Chicago, 1981, p. 263: "The intentionality that I am claiming for the novel, in the face of more disingenuous critical formalisms which I would argue, simply displace or disguise this essential historical notion, is not a simple matter. It is the product of intersecting intentions: of the novelist, of the novel as a particular kind of writing, and of the shifting formalities of the larger cultural context. It is an intentionality that can only be reconstructed from its effects - the effects of the texts on the changing community of its readers". 
ciones humanas y de la intencionalidad de las obras. Es importante esta aclaración para evitar malentendidos sobre si se puede hablar rigurosamente de las intenciones de personas no presentes.

Reyes concluye el primer apartado con la observación fundamental de que sólo hay literatura cuando ambas intenciones se juntan. Otra vez estoy de acuerdo, pero parcialmente. Aparte de la intención del autor de lograr un sistema de significantes apropiados y de comunicar algo, también es necesario que haya una intención de recibir y realizar el texto por parte del lector. La literatura, a mi parecer, se da en el encuentro entre la intencionalidadidel texto (que, claro está, fue resultado de las intenciones del literato) y la intención recreadora del lector.

2. Reyes hace bien en llamarnos la atención sobre la reducción equívoca de mimesis a mera imitación; sería más exacto decir que mimesis señala re-creación ${ }^{2}$. También acierta al usar el término intención en el plural cuando se refiere a los lectores. Si tomamos en cuenta la distinción que hemos introducido en la discusión - la intencionalidad de la composición humana y la intención del lector- podemos aceptar plenamente la última aclaración de este apartado:

[ficción] indica, por una parte, que añadimos una nueva estructura - probable o improbable - a las que ya existen. Indica, por otra parte, que nuestra intención [como lectores] es desentendernos del suceder real. Finalmente, indica que traducimos una realidad subjetiva.

La lectura de una obra de ficción es, precisamente, dar realidad a una coherencia nueva, la que hemos podido y tenido que hacer para poder leer. Tampoco cabe duda de que la lectura de ficción es la forma más común de hacernos variantes del mundo en que vivimos y que, por lo tanto, siempre es una traducción. Es decir, que lo que fue en el escritor realidad subjetiva se ha he-

${ }^{2}$ El concepto amplio de mimesis lo ha presentado PaUL Ricoeur en "Tiempo y narración. La triple mimesis", que forma el cap. 3 del t. 1 de "Configuración del tiempo en el relato histórico" en Tiempo y narración, Cristiandad, Madrid, 1987, pp. 117-172. Para la definición inicial véase p. 86: "El mismo criterio debe emplearse en la traducción de mimesis (en la poética de Aristóteles): dígase imitación o representación (según los últimos traductores franceses), lo que hay que entender es la actividad mimética, el proceso activo de imitar o representar. Se trata, pues, de imitación o representación en su sentido dinámico de puesta en escena, de trasposición en obras de representación". 
cho texto y la lectura del texto es una traducción de una realidad subjetiva a otra, la nuestra. El problema para la ciencia de la literatura ya se percibe: ¿cómo compartir experiencias de realidad subjetiva? ¿Cómo decir algo que no sea mera impresión mía? ${ }^{3}$

3. Reyes nos plantea ahora la problemática de la referencialidad del texto literario. Pero aquí nos incomoda aún más la ambigüedad del término intención. Tendremos que ampliar el comentario alfonsino:

La experiencia psicológica vertida en una obra literaria puede o no referirse a un suceder real. Pero a la literatura tal experiencia no le importa como dato de realidad, sino por su valor atractivo, que algunos llaman significado ${ }^{4}$ La intención no ha sido contar algo

${ }^{3} \mathrm{El}$ problema de la subjetividad ha sido el obstáculo a toda poética que tome en cuenta la realización individual. La base de la respuesta está en la colectividad originaria de toda lengua humana y la función comunicativa de todo texto escrito u oral. Véase sobre la subjetividad a ÉMILE BENVENISTE, "De la subjetividad en la lengua", Problemas de lingüistica general, t. 1, Siglo XXI, México, 1971.

${ }^{4}$ Los términos significado/significante tienen su origen en la obra de Saussure, pero han cobrado su fuerza analítica con el estructuralismo francés, especialmente en la obra de Roland Barthes y Gérard Genette. El significante como vehículo conductor se puede examinar por su propia cuenta, separado de su producto, que es el significado. También se debe tomar en cuenta la crítica al respecto hecha por JACQUEs DeRrida, De la grammatologie, Éds. de Minuit, Paris, 1967, pp. 25-31, donde insiste en que la distinción y, por lo tanto, la separación de los dos términos es una ficción útil ya que todo significante es inseparable de su significado en la enunciación misma. Aquí se usan los términos como vehículo heurístico de análisis. Véase el comentario preciso de Sarah Kofman referente al papel del pensamiento de Derrida sobre la escritura en Lectures de Derrida, Éds. Galilée, Paris, 1984, pp. 39-40: "Si, à la lettre, l'écriture ne veut rien dire, elle n'est pas absurde: l'absurdité fait système, en la renversant, avec l'affirmation métaphysique du sens. Ne rien vouloir dire c'est entrer dans le jeu, "dans le jeu de la différence qui fait qu'aucun mot, aucun concept, aucun énoncé majeur ne viennent résumer et commander, depuis la présence théologique d'un centre, le mouvement et l'espacement textuel des différences. [...] Je me risque à ne rien vouloir dire qui puisse simplement s'entendre, qui soit simple affaire d'entendement. A s'enchevêtrer sur des centaines de pages d'une écriture à la fois instant et elliptique, imprimant [...] jusqu'à ses ratures, emportant chaque concept dans une chaîne interminable de différences, s'entourant ou s'embrassant de tant de précautions, de références, de notes, de citations, de collages, de suppléments, ce ne rienvouloir-dire n'est pas [...] un exercice de tout repos". (Positions, pp. 23-24). Le jeu produit des effets de sens: pour être entendus comme tels, comme simulacres, il est nécessaire qu'ils aient été inscrits non sur la paroi interne de l'oreille mais sur une paroi plus subtile apte à faire résonner le sens pluridi- 
porque realmente aconteciera, sino porque es interesante en sí mismo, haya o no acontecido.

La literatura como conjunto de la creación verbal humana no tiene una voluntad orientadora en sí. La referencialidad al mundo de acción que es la base de toda expresión en lengua humana, a veces es designación de tal o cual situación, pero también puede ser una expresión metafórica ${ }^{5}$ en que esta referencialidad se encuentra en un eclipse parcial porque la expresión tiene como propósito no tanto referirse sino provocar una reacción creativa en el lector. Sea cual fuere la intención del autor, el hecho indiscutible es que en la obra literaria la referencia tiene una función más compleja que la de señalar y ésta es la función estética de realizar cierta situación creativa en sus lectores. Por lo tanto, repetimos, la intencionalidad del texto se encuentra y se realiza con la intención del lector de leer y entender.

4. Reyes insiste en que la intención estética es la de lograr la forma literaria. Sin embargo, esta intención de parte del poeta sólo se conoce por lo que ha escrito. Aun en sus declaraciones personales más fidedignas es imposible separar propósitos de hechos. Tampoco olvidemos que en la mayoría de los casos los poetas mismos no se dan plenamente cuenta de lo que han logrado. Repetimos otra vez, miremos a los hechos y dejemos los propósitos para la especulación ociosa ${ }^{6}$. ¿Y cuáles son los hechos? Los hechos son

mensionnellement, à le faire s'écarter de lui-même en tous sens: à le disseminer".

${ }^{5}$ La metáfora es un tópico de riquísima discusión en la lingüística y en la teoría literaria. Aquí seguimos la teoría de la metáfora escindida elaborada por Paul Ricoeur en La metáfora viva, tr. Agustín Neira, Cristiandad, Madrid, 1980.

${ }^{6} \mathrm{El}$ crítico norteamericano E. D. HIRSCH en su libro Validity in interpretation (Yale University Press, New Haven, 1967) ha hecho el esfuerzo más completo para rescatar las intenciones del autor como criterio de interpretación. En la p. 13 escribe: "Its saying has no determinate existence but must be the saying of the author or a reader", y continúa más adelante en la p. 24: "Since it is very easy for the reader of any text to construe meanings that are different from the author's, there is nothing in the nature of the text itself which requires the reader to set up the author's meaning as his normative ideal". Y, en la p. 31: "Verbal meaning is whatever someone has willed to convey by a particular sequence of linguistic signs..." Nuestra oposición al argumento de Hirsch se resume de la manera siguiente: el autor no está presente, sólo tenemos el texto. Estamos de acuerdo con que el significado del texto tiene dos momentos históricos, el que tuvo el autor en el pasado, y el que tiene el lector 
la obra escrita del poeta. La obra en sí tiene diseño, plan, desarrollo, estructura, estilo y ésos son los hechos que declaran la intencionalidad del texto.

Hagamos una pequeña digresión para mostrar un comentario sobre intencionalidad textual. Leemos:

\author{
Amanecía tu voz \\ tan perezosa, $\tan$ blanda \\ como si el día anterior \\ hubiera \\ llovido sobre tu alma?.
}

Esta estrofa empieza con una enunciación que recuerda el pasado dirigiéndole la palabra a un tú que no responde. El recuerdo se concentra en la evocación de la voz del tú: el recuerdo de la particularidad de esa voz lleva dentro toda la presencia del tú que está ausente en el presente implícito de la enunciación misma. La estrofa, primera de cinco en un poema de Jaime Torres Bodet, nos ofrece a un yo enunciante recordando lo escuchado sin decirnos lo que se dijo. La enunciación se concentra en el acto mental de recordar. Lo que es la presencia de la voz de su tú dentro del recuerdo está ausente de la enunciación misma.

Esta voz enunciante del yo caracteriza a la voz de su tú como perezosa y blanda. Pero el enunciante busca recobrar el recuerdo aún más nítidamente a través de una comparación: la voz recordada es tan blanda como si el día anterior hubiera llovido sobre su alma. Esta lluvia del alma aumenta e intensifica no solamente la añoranza, sino a la vez lo efímero del recuerdo ante la realidad temporal dominada por la ausencia. No es éste el lugar de extendernos a comentar todos los aspectos formales, referenciales y figurativos del poema. Sencillamente el propósito de esta divagación es insistir en que el diseño mismo del texto tiene que leerse como acción creativa intencional y como sistema comunicativo, como composición cuya intencionalidad se comprende independientemente de cualesquiera que hayan sido las intenciones personales del autor.

5. Pide Reyes que el contenido de la obra literaria se conside-

en el presente. El del pasado sólo ha dejado huellas, el del presente se puede expresar, analizar, discutir : debatir, y ésa es la función de la crítica literaria.

7 Primera estrofa del poema intitulado "Música", que forma parte del libro Biombo, publicado en México por Jaime Torres Bodet en 1925. 
re como experiencia estética más que como conocimiento en un determinado orden. Pero con rigor también insiste en que esta experiencia estética no es un transportarse subjetivamente sino un recobrar la experiencia humana de otro que fue escrita para ser comunicada. Nos dice: "Es cosa de parapsicología el componer poemas para entenderse solo y ocultarlos de los demás".

6. La comunicación, como fundamento de la literatura, hace de la belleza de la expresión un efecto y no una meta. Según Reyes, el lenguaje tiene un triple valor que la literatura pone en juego creativo: el sentido, el ritmo y lo espiritual. A nuestro juicio queda inacabado el comentario de don Alfonso cuando explica la expresión literaria como emoción o "humedad espiritual". Sería más eficaz hablar de la capacidad evocativa del texto y no valerse de lenguaje tan obscuro como "humedad espiritual".

Este tipo de explicación tiene una historia muy digna, desde lo sublime de Kant hasta el élan vital de Bergson. Sin embargo, la fuerza de la crítica literaria reside en el desarrollo y la eficacia de sus medios de explicación. Entiéndase bien, no se explica para agotar el texto poético sino para traducir el sentimiento de la humedad espiritual del reino de lo subjetivo a la participación de la intersubjetividad. La experiencia de lectura de la poesía es nueva cada vez; por lo tanto, no se puede reducir a una indagación de causas formales. El lenguaje evasivo que emplea aquí Alfonso Reyes establece lo que su tradición crítica ha demostrado que son los límites de su comunicación. Pero a cincuenta años de distancia, tenemos otros medios y tomamos otras iniciativas que extienden la suya. La iniciativa de una profundización en el texto es la que compartimos con Reyes; la iniciativa de nuestra expresión es la que añadimos. Buscamos una explicación que presente con mayor claridad nuestra situación existencial como lectores.

7. Este párrafo demuestra los vínculos del pensamiento de Reyes con la fenomenología de Husserl y también la necesidad que sintió de distanciarse al no encontrar lazos directos con la crítica literaria. Por los mismos años en que Alfonso Reyes escribía este ensayo, en plena guerra mundial, otro pensador, Hans-Georg Gadamer, buscaba salvar su cordura ante la barbarie nazi de su país y desarrollaba páginas afines a las del mexicano. Reyes escribe que entre la expresión del autor y la comunicación que se nos transmite no hay una relación fija. "La representación del mundo, las implicaciones psicológicas, las sugestiones verbales, son distintas para cada uno y determinan el ser personal de cada hombre." Es en esa comunicación, en el transcurso del texto virtual a la rea- 
lización por parte del lector, donde están la meta y el valor de la literatura. La fuerza de mimesis es la de re-presentar, no de imitar, y en esta nueva presentación, dentro de la imaginación del lector, hay una creación del mundo que cumulativamente hace a cada hombre lo que es como ser pensante. Cuando escribe don Alfonso que el estudio del fenómeno literario es "una fenomenografía del ente fluido" y nos aclara en una nota explicativa que usó fenomenografía en vez de fenomenología para evitar confusiones, nosotros respondemos que el término de Porfirio Parra está muy lejos de su pensamiento, además de ser una torpeza intelectual. El término que busca Reyes lo daría Gadamer, después de la guerra, en 1960, tarde para don Alfonso, pero no para nosotros, y es hermenéutica fenomenológica en vez de fenomenología. Termina Reyes este párrafo fundamental con la siguiente observación: "De aquí que cada ente literario esté condenado a una vida eterna, siempre nueva y siempre naciente, mientras viva la humanidad". Estoy de acuerdo.

8. Al tratar el fenómeno creativo de la lengua, Reyes propone designarlo indistintamente con el término literatura o poesía, y al referirse al escritor o al lector usar el término literato. Es una lástima que no elaborase esta nomenclatura, ya que señala inequívocamente el papel creativo del lector, lo que no sería parte de nuestro mundo intelectual hasta la década de los setenta, notablemente con los estudiosos de Constanza, Wolfgang Iser y Hans Robert Jauss ${ }^{8}$.

9. Éste es otro párrafo breve, pero lleno de significado: “Discrimen esencial: no confundir nunca la emoción poética, estado subjetivo, con la poesía"'. Nosotros diríamos lo mismo, pero armados de conceptos teóricos elaborados en estos cincuenta años que nos separan del ensayo de Reyes. Para nosotros es esencial discriminar entre el texto virtual, es decir, la obra en potencia que espera a cada nuevo lector y a su lectura, de la experiencia de la lectura misma, que es desde luego el foro subjetivo de cada lec-

${ }^{8}$ La teoría de la recepción ha tenido un desarrollo global desde fines de los años sesenta. Esta coincidencia en países tan distintos como Alemania y el Canadá se debe a la marcada influencia de la filosofía fenomenológica en centros de estudio en que se emprendía la tarea común de la teoría literaria. La nueva Universidad de Constanza empezó las cátedras de literatura con antiguos compañeros de estudio en Heidelberg, donde Hans-Georg Gadamer había llevado la fenomenología de Heidegger directamente a los estudios literarios. Hans Robert Jauss ocupó la cátedra de lenguas románicas y Wolfgang Iser la de lengua inglesa. 
tor. Finalmente, también separamos a ambos del comentario crítico sobre la experiencia de lectura, que como comentario es comunicación intersubjetiva del entendimiento forjado por los medios de explicación.

10. Dice Reyes que la poesía es un combate contra el lenguaje: “De aquí su procedimiento esencial, la catacrisis, que es un mentar con las palabras lo que no tiene palabras ya hechas para ser mentado. Sea, pues, bienvenido el desajuste, al cual debemos la poesía". En nuestros términos, Reyes ha señalado una teoría tensional de la metáfora. En esta teoría la impertinencia semántica de los términos se debe precisamente al desajuste denotativo entre ellos. Este choque creativo obliga al lector a suspender la referencialidad natural del lenguaje como comunicación cotidiana y emprender la referencialidad escindida del lenguaje como comunicación creativa ${ }^{9}$.

11. Reyes considera el drama, la novela y la lírica como las funciones literarias. Es decir, el texto literario comparte estas funciones expresivas que son funciones y no géneros porque organizan al texto. Aquí Reyes está de acuerdo con el teórico suizo Emil Steiger y el alemán Ernst Junker, que consideran a la función expresiva de las tres personas de toda lengua humana como fundamento de organización que con el tiempo han llegado a ser consideradas como categorías. El estudioso alemán Wolfgang Kayser las denomina actitudes estéticas. Preferimos el concepto de Reyes de función estética ${ }^{10}$.

12. Añade Reyes aquí una aclaración sobre funciones y géne-

${ }^{9}$ En La metffora viva RicoEUR expone por primera vez su teoría tensional de la metáfora, en la cual la fuerza opuesta, derivada de la misma impertinencia semántica, es la que se distingue de la metáfora decorativa o la desgastada. Ricoeur insiste en el conflicto implícito entre la referencialidad literal que queda en eclipse por la referencialidad textual. El eclipse es un concepto necesario para la continuidad tensional, pues si se tratara de la abolición de toda referencialidad literal no habría impertinencia o creatividad.

${ }^{10}$ Los libros esenciales para el estudio del género literario en nuestra época siguen siendo el de WOLFGANG KAYSER, Interpretación y análisis de la obra literaria, Gredos, Madrid, 1954, y la obra de EMIL STEIGER, Grundbegriffe der Poetik, $6^{\mathrm{a}}$ ed. rev., Bern, 1963. Steiger y Kayser desarrollan una radical renovación del concepto del género literario de la filología tradicional, que ha tenido su mayor influencia entre los estudiosos europeos, mas no entre los americanos. La notable excepción es el trabajo del profesor norteamericano PAUL HERNADI, Beyond genre: new directions in literary classification, Cornell University Press, Ithaca, 1972. Dedico un capítulo a estos problemas en Shadows in the cave: a phenomenological approach to literary criticism based on Hispanic texts, University of Toronto Press, Toronto, 1982. 
ros: "Drama, novela, lírica: funciones, no géneros. Procedimientos de ataque de la mente literaria sobre sus objetivos. Los géneros, en cambio, son modalidades accesorias, estratificaciones de la costumbre en una época, predilecciones de las pasajeras escuelas literarias"'. En mis términos, al hablar de una función literaria se habla del mismo fenómeno, la realización estética, que es el encuentro texto-lector, y hablar de géneros literarios es hablar de un recurso histórico para organizar nuestro entendimiento del pasado en el presente.

13. La relación vigente que explica Reyes entre función literaria y género literario aclara hábilmente su procedimiento como historiador de la literatura. El género pierde toda la rigidez de categoría al convertirse en la designación que una época le ha dado a la realización de una de las funciones literarias (drama, novela y lírica), tal y como las elaboraron esos escritores o como han visto esa elaboración los historiadores.

14. Reyes afirma que el estudioso no puede permitirse confundir la experiencia de lectura con la obra en sí, la cual siempre es texto inagotable. Históricamente Reyes está reaccionando contra el impresionismo crítico de su época.

15. Todas las funciones literarias re-presentan a la realidad; el drama de modo más directo, la novela a través de fantasmas psicológicos y la lírica en lo más básico, que es la voz enunciante pura. Kayser seguramente había leído estas observaciones de Reyes al escribir su obra entre 1940 y 1946.

16. Para Reyes la función lírica se aparta de las otras en que se distancia del acontecimiento fingido que nutre tanto al drama como a la novela. Nosotros añadimos que la función lírica tal como la concibe Reyes hace de la enunciación su propio acontecimiento. Lo que se realiza no tiene la estructura binaria de la novela, en la que hay un tiempo narrativo y un tiempo de realización en la lectura o en el drama, donde el acontecimiento siempre es el presente de la representación en las tablas, al que el espectador está completamente atado. En la lírica el acontecimiento es la lectura que el lector controla ${ }^{11}$.

${ }^{11}$ La lectura de la poesía difiere de la lectura de otras modalidades literarias en dos características esenciales, una de tipo pragmático, otra estética. La lectura de la poesía se suele realizar sin interrupción, aun en el caso de los poemas más largos como The waste land o Piedra de sol, lo cual es imposible con obras como La guerra y la paz, Fortunata y Jacinta, o La montaña mágica. La poesía constantemente obliga al lector a superar el texto -realizando la fuerza evocativa de imágenes y metáforas. Los otros géneros llenan usualmente lar- 
17. ¿La función lírica es entonces la libertad creadora misma? Reyes profundiza; más que libertad es liberación, puesto que se rige por exigencias formales, tiene toda una disciplina, pero es liberación en cuanto a la lectura. El lector no se encuentra ni sujeto al acontecimiento de la escritura ni a la representación de ésta.

18. En esta entrada Reyes discute las diferencias entre verso y prosa. Se supone que la prosa está más cerca del habla que el verso porque se aproxima más al uso cotidiano de la lengua. Pero nosotros añadimos que éste es un prejuicio de una sociedad formada por la escritura. La lengua escrita en prosa o en verso está igualmente distante de la lengua hablada. El verso fue parte de una cultura oral al haber sido uno de los modos de narrar en la tradición épica. La prosa se desarrolló con el lenguaje escrito de una base más bien codificante de leyes y dogma. Ninguno de los dos representa al habla en sí. Aun la simulación en el diálogo de la novela o del teatro moderno tiene un contexto circunscrito textualmente, lo cual es completamente ajeno al habla. El habla es la génesis de toda lengua humana y el lenguaje escrito, en verso o prosa, es la derivación simbólica de la sociedad moderna ${ }^{12}$.

19. Reyes aclara que no hay jerarquía en la lengua literaria entre prosa y verso, sólo hay distintos usos: "Ni verso ni prosa literarios pueden confundirse con el habla común". Pero nosotros agregamos que la diferencia no reside ni en la forma ni en el asunto, sino en la recepción del conjunto. Leemos el verso en forma muy diferente de la prosa.

20. Reyes introduce acertadamente un tercer elemento. Además del habla de cada día y del lenguaje literario, nos recuerda que hay un lenguaje científico: "El lenguaje científico procura abolir el halo de indeterminación subjetiva que irradia la palabra para poder mentar fijamente lo que conoce"'. Hasta cierto punto tiene razón don Alfonso, pues el lenguaje literario fecunda a la indeterminación aunque rodeado de elementos determinados, y el lenguaje científico busca comunicar sólo lo determinado. Pero

gos pasajes de desarrollo de acción, acontecimiento y escena. Quizá el factor más notable de la literatura hispanoamericana de la post-modernidad es que se aproxima más que la narrativa anterior a esta situación común en la lectura de la poesía.

${ }^{12}$ Con respecto a la importancia de la literatura de tradición oral en el desarrollo de la épica, véase el estudio fundamental de ALBERT B. LORD, The singer of tales, Harvard University Press, Cambridge, 1960. Lord aclara no solamente el proceso creativo de Homero, sino que también demuestra las diferencias distintivas de la épica oral a la escrita. 
sería más correcto describir la diferencia entre el lenguaje científico y el literario como proposiciones inversas de la misma búsqueda de la realidad. La realidad científica no es la proposición expresada en sus textos sino el enfrentamiento de esas proposiciones con el mundo de la acción. Igualmente, la realidad literaria no es el texto en sí sino la apropiación de ese texto a través de una lectura.

21. En este párrafo Reyes expone algunas de sus ideas sobre historia literaria. Nos dice que la historia literaria no se puede trazar como la historia política o económica, aun dentro de las limitaciones arbitrarias de una literatura nacional. Es necesario un concepto más amplio para emprender una historia literaria. No solamente hay la necesidad de tomar en cuenta el orden temporal de los autores y sus obras y la geografía de su contingencia al convivir, sino que también hay que notar la presión constante del pasado en el presente y de la literatura transmitida por la traducción.

22. Haciendo un repaso de los términos operativos de historia literaria: literatura universal, historia literaria de época, literatura comparada y literatura mundial, Reyes recoge la última como explicación del pensamiento literario. Don Alfonso considera la historia de la literatura mundial como un inventario de obras y hechos que afectan a nuestra civilización, que están vivos todavía en la mente, que han trascendido, que siguen operando. Pero no nos explica cómo sortear la deformación de los caprichos individuales de la literatura funcional. A nuestro parecer, este tipo de historia literaria es una historia de la creatividad en el presente. Las obras que tienen actualmente la capacidad de provocar esa redescripción del mundo son nuestro pasado efectivo, con el que hemos hecho y estamos haciendo el presente ${ }^{13}$.

23. Si todo estudio histórico de las literaturas presupone un índice de obras y autores significativos, ¿quién tiene autoridad para elaborar estas listas para los demás? La única respuesta es que cada estudioso de la historia literaria lo hará dentro de sus límites y que la comunidad de estudiosos lo juzgará.

24. Reyes identifica a esta participación en la historia de la

${ }^{13} \mathrm{El}$ trabajo más notable en la renovación de la historia literaria es la obra de Hans Robert Jauss. Véase como ejemplo "La función social de la experiencia lírica y su sistema comunicativo en el entorno de 1857", en Experiencia estética y hermenéutica literaria, tr. Jaime Siles y Ela Fernández Palacios, Taurus, Madrid, 1986, pp. 419-430. Ésta es la traducción de una parte de Asthetische Erfahrung und literarische Hermeneutik, Fink, München, 1977. Cito del original. 
literatura mundial como la lectura compartida, nosotros la llamamos la comunidad de estudiosos.

25. Ya que la literatura se ofrece en forma de lectura se presenta el problema del entendimiento: ¿cómo compartir la experiencia personal dentro de una comunidad de lectores? La respuesta va dirigida al lector general y no al estudiante metódico o al universitario. Reyes aconseja leer los textos, los comentarios sobre estos textos y las historias literarias y levantar poco a poco el propio edificio de la literatura mundial de "conformidad con su prejuicio". Podemos agregar que este procedimiento se separa del desarrollo del lector crítico sólo en la intensidad, mas no en la orientación.

26. Para leer el texto literario se necesita, además del conocimiento de la lengua en que está escrito, una actitud activa de responder a las exigencias del texto. El lector que espera ser transportado por el texto quedará limitado a la superficie del acontecimiento de ficción. Reyes se explica: "lo primero es penetrar la significación del texto", lo cual demanda voluntad, propósito y dirección por parte del lector. Añade don Alfonso: "Esto supone entender lo mentado y también la intención con que se lo mienta". Diríamos nosotros por intención, intencionalidad o diseño del texto.

27. Aunque al leer estamos ante el lenguaje escrito, Reyes insiste en percibir interiormente una repercusión fonética en las secuencias verbales, un movimiento y un ritmo.

28. Responder a las imágenes y a las metáforas exige más de parte del lector en ciertos textos que en otros. El sentido metafórico puede ser una extensión sensorial de un sentido básico de la lengua, como lo es en el ejemplo que cita Reyes de Góngora: "Espejo de zafiro fue luciente / la playa azul, de la persona mía". Es decir, el poeta ha cambiado el orden natural del castellano para crear un efecto. Puesto en forma prosaica diría: La playa azul fue luciente espejo de zafiro de la persona mía. Pero no cabe duda que el verso "la playa azul, de la persona mía" en sí expresa un conjunto audaz. Y ese amigo poeta que menciona Reyes, que prefería leer al verso sin su contexto sintáctico, estaba leyendo una metáfora audaz derivada de la de Góngora, puesto que "la playa azul, de la persona mía" bien pudiera decir en otro poema que la persona en sí es el espejo de zafiro luciente en que se refleja el mundo.

29. He aquí una explicación importante de Alfonso Reyes: "Las asociaciones erráticas del lector, recuerdos personales que 
se le atraviesan, perturban la atención sobre el texto al punto de desviar su sentido". Claro está; pero nos dice que todos traemos un repertorio de respuestas ya hechas que se disparan a la más leve provocación y lanzan a nuestra mente por zonas ajenas a la lectura. Lástima que don Alfonso no pudiera debatir este punto con desconstruccionistas como Harold Bloom ${ }^{14}$.

30. Reyes insiste en que hay que tener la voluntad y disposición de responder al texto y no distorsionarlo a nuestro antojo, ni tampoco según nuestra idea de lo que debería ser a partir de la lectura de otras obras.

31. La lectura ha provocado cambios radicales en el ser humano, dice Alfonso Reyes. Tanto Marshall McLuhan como Walter Ong están de acuerdo ${ }^{15}$. Nosotros reconocemos que se han perdido ciertos modos de convivir en la comunidad al dejar la oralidad, pero también, como ya hemos señalado, se ha ganado una riqueza incalculable de liberación de las circunstancias de nuestras limitaciones de tiempo y espacio. Sin embargo, queda implícito en estas observaciones, tanto las de Reyes como las nuestras, que hay una enorme dificultad en que comunidades orales convivan con comunidades de lengua escrita, como ocurre en la realidad mexicana.

32. La literatura, según Reyes, como la lengua misma, es una expresión colectiva que siempre está en proceso, siempre se está renovando como el famoso surtidor de agua de Bergson. El pasado siempre se rehace, pero se rehace de manera nueva y original a través de la lectura. Estamos de acuerdo.

No discuto de ningún modo la validez de la teoría de Alfonso Reyes, que es, ciertamente, la más abierta y filosóficamente informada de su época. El comentario que he hecho, como complemento a la exposición del pensamiento de don Alfonso, sigue el camino inverso de su especulación. Reyes se interesa por darle

14 Según Harold Bloom, la lectura literaria es una empresa casi imposible si se quiere reproducir la obra escrita por el autor, y si la lectura es un esfuerzo serio de un lector hábil y enterado será seguramente una lectura falsa (misreading). Véase al respecto su libro $A$ map of misreading, Oxford University Press, Oxford, 1975.

${ }^{15}$ La obra clave de Marshall McLuhan es The Gutenberg galaxy: the making of typographic man, University of 'Toronto Press, Toronto, 1962. Entre las obras de WALTER J. ONG véase Interfaces of the word, Cornell University Press, Ithaca, 1977 y, sobre todo, Orality and literacy, Methuen, London, 1982, especialmente "Print, space and closure", pp. 117-138. 
orden y orientación al estudio de la literatura. Yo, en cambio, me propongo exponer las características de los estudios literarios, partiendo del comentario crítico que desarrolla un papel histórico como glosa de los textos literarios que se han comentado.

Me veo enfrentado a la pregunta de la función histórica de la crítica porque reconozco el hecho, señalado por Reyes, de que la crítica es ante todo un diálogo para el bien de los dialogantes. Pero crece imperativamente la duda de si la crítica lega algo, para bien o para mal, que afectará la lectura de los textos de futuras generaciones. Entonces, impulsado por esta duda, utilizo un método regresivo que me conduce desde la situación histórica del crítico hacia la capacidad básica de comprender la literatura y comentarla. Ahora bien, esta capacidad encierra características temporales de la época del crítico y la relativa distancia que reconoció entre su comentario y el texto que comentó. Lo que verdaderamente permanece en la posición narrativista del crítico y que no suprime de ninguna manera el carácter dialogal de su explicación, es que un acontecimiento, tanto del escritor literario como del escritor crítico, es histórico en la medida en que contribuye a la progresión de una historia susceptible de ser contada, como bien lo ha entendido René Wellek en su historia de la crítica ${ }^{16}$. En este sentido, un acontecimiento narrativo se distingue de un acontecimiento cualquiera por su lugar posible en un relato.

Hay importantes razones por las que debemos mantener separadas a la historia de la crítica por una parte, de un texto o de una sucesión de textos que llamamos la literatura, por la otra. Daré algunas de las razones más importantes. El trabajo de explicación se aleja del texto mismo al tener que tomar una postura fuera de la órbita del texto literario; la crítica utiliza una construcción de modelos explicativos ajenos al texto; los intereses del crítico y del texto son divergentes y sólo se juntan en la intencionalidad de la comunicación. He aquí la clave para responder a nuestra pregunta sobre el legado de la crítica literaria. Se trata del problema de la comunicación sobre el arte literario, no solamente entre personas vivientes, sino entre contemporáneos, también predecesores y su-

${ }^{16}$ La obra maestra de René WeLLEK es su historia de la crítica literaria moderna publicada en seis volúmenes, y a la fecha aún sin terminar. La base de esta historia ya la había propuesto en su famosa Theory of literature, escrita con AUSTIN WARREN en 1949, donde señala que la crítica como ciencia se distingue de la evaluación cultural de las obras de arte en que la crítica como ciencia humana se elabora dentro de su propia tradición de glosa o comentario, y no como apéndice de la obra de arte. 
cesores, en el sentido en que Alfred Schutz ha usado estos términos ${ }^{17}$. Una herencia comunitaria no es transmitida de uno a otro en su singularidad, sino a través de una tradición de acción e intereses comunes. Es siempre una comunidad, no un individuo, la que retoma la tradición de hacerse. Este acto comunitario de repetición de comentarios sobre la literatura es, a la vez, un acto de fundación de su propia identidad y también, posteriormente, lo que hace posible diferenciar lo nuevo de lo viejo para que nuevas generaciones puedan forjar su identidad. Por lo tanto, todo trabajo crítico cumple esta doble función y la cumple relativamente mal o bien, medida por su participación en la comunidad. He respondido a este doble imperativo. A otros toca juzgar si he participado en mi comunidad de comentaristas.

Mario J. Valdés

University of Toronto

17 Véase al respecto ALFRED SCHUTZ, The phenomenology of the social world, Northwestern University Press, Evanston, 1967. Ésta es la traducción del original de 1932. En la p. 207 escribe: "What is of special concern to us, however, is that the line separating present social reality from the world of predecessors is fluid". Continúa con un segundo punto, necesario para nuestros propósitos, en la p. 209: "I come to know the world of my predecessors through records and monuments. These have the status of signs, regardless of whether my predecessors intended them as signs for posterity or merely for their own contemporaries. [ . . I I know that every sign has its author and that every author has his own thoughts and subjective experiences as he expresses himself through signs. It is therefore perfectly proper for me to ask myself what a given predecessor meant by expressing himself in such and such a way. Of course, in order to do this, I must project myself backward in time and imagine myself present while he spoke or wrote". Amplía estos conceptos en las páginas siguientes hasta llegar a su conclusión de que nunca podemos conocer realmente al autor del pasado ya que lo que conocemos es su obra vista desde nuestro mundo. En la p. 211 escribe: "However, I have no way of making sure that my interpretive scheme coincides with my predecessor's expressive scheme when he made use of the signs in question". Su conclusión, p. 214 merece nuestra atención: "The whole world of successors is by definition nonhistorical and absolutely free. It can be anticipated in an abstract way, but it cannot be pictured in specific detail. It cannot be projected or planned for, for I have no control over the unknown factors intervening between the time of my death and the possible fulfillment of the plan". 